\title{
Arc Light Sensing of Droplet Transfer and Its Analysis in Pulsed GMAW Process*
}

\author{
By Qi Long WANG**, Pen Jin LI*** and Masaaki NAKA****
}

\begin{abstract}
A new method and its principle for sensing droplet transfer in GMAW of steel and aluminum alloy have been researched in this paper. A practical arc light sensing and controlling system has been developed. The reliability of the arc light characteristic signal that indicates droplet detachment and the control accuracy of the system have been verified using high-speed photography. Based on the mathematical model set up in the paper, the mechanism of the signal and relative phenomena were analyzed. The parameters which infuence arc light radiation were given and the limitation of this sensing method was discussed.
\end{abstract}

Key words: Pulsed GMAW, Droplet transfer, Arc light sensor, Welding process control

\section{Introduction}

Gas metal arc welding has made a rapid progress in recent decades. However, the consistency of the resultant weld quality still needs to be researched, which is closely related to the stability of droplet transfer.

The introduction of pulsed GMAW offered the opportunity to conveniently control droplet transfer and one pulse one droplet (OPOD) transfer mode is generally recongized as the optimum transfer mode ${ }^{1-6)}$. A significant amount of works have been published on the methods that can provide transfer mode when welding parameters are kept constant. However, these preliminary works are limited to the preset welding parameters obtained through experimentation or theoretical calculation ${ }^{5,7-12)}$. It is known as one-knob open-loop control.

It is known, however, that welding parameters (especially wire feed speed and arc length) are difficult to be kept constant during welding. For this reason, adaptive control systems with feedback control of some welding parameters, have been developed ${ }^{2-6)}$. The direct object of adaptive control is not to control the droplet transfer. Therefore, it is still a type of open-loop control and impossible to provide reliable OPOD transfer. In order to control the droplet transfer directly, the only feasible way is to find reliable sensing methods for droplet transfer.
High speed photography and optical image are reliable methods for observing droplet transfer, however, presently they are not suitable for the real time sensing and control of droplet transfer. An amount of works on other sensing methods, such as acoustic emission and arc sound sensing, have been presented ${ }^{13-17)}$, but they were all very susceptible to ambient noise. The electrical signal sensing method (arc voltage, welding current ${ }^{2,8,14,16,18-26)}$ is only effective for short circuit transfer and globular transfer processes, but not for spray transfer process because the signal-to-noise ratio is too low (for example, of steel, $0.5 \mathrm{~V}<\Delta \mathrm{V}<1 \mathrm{~V}$ ). The elecctrical signal for sensing aluminum alloy droplet transfer is relatively better ${ }^{19}$, but it still needs to be improved for real time control.

Arc light sensing is a promising method for sensing droplet transfer, and has already been used by some researchers ${ }^{18,27)}$. However, the signal-to-noise ratio of the arc light signal is comparatively low. There is no work about the OKOD transfer. The sensors in previous works are not practical, for instance, difficult to adjust, clumsy or expensive.

The purpose of the work presented in this paper is to develop a novel practical arc light sensing and control system, and to explore the physical essence of arc light signal variation during projected droplet transfer in pulsed GMAW of steel and aluminum alloy.

\footnotetext{
* Received : 25 March 1996.

**Non-Member, Department of Welding Engineering, Harbin Institute of Technology, Harbin, P.R. China

***Non-Member, Ph. D., Department of Welding Engineering, Harbin Institute of Technology, P.R. China

****Member, Joining and Welding Research Institute, Osaka University, Japan
} 


\section{Experimental procedure}

All experiments were performed with bead-on-plate welding. Mild steel (AWS ER70s-3) and aluminum alloy (AA1100) workpieces were respectively $250 \times 80 \times$ $10 \mathrm{~mm}$ and $200 \times 100 \times 5 \mathrm{~mm}$. In steel welding, $1.2-\mathrm{mm}$ diam. steel welding wire (AWS ER70S) was used and the shielding gases were pure argon and argon-rich gases $\left(\mathrm{Ar}-\mathrm{CO}_{2}, \mathrm{Ar}-\mathrm{O}_{2}\right)$ with flow rate of $15 \mathrm{~L} / \mathrm{min}$. In aluminum welding, 1.6-mm-diam. aluminum alloy welding wire (AA4043) was used and the shielding gas was pure argon with flow rate of $25 \mathrm{~L} / \mathrm{min}$.

The main welding equipment was a transistor welding power supply MM350 (OCR) (was adjusted for experiment requirements), a MILLER wire feeder (S-54D) for steel and a PLANETIC wire feeder (Mercury 501) for aluminum. The power supply provided a total peak output current of over $450 \mathrm{~A}$. In pulse mode, the background current was $50 \mathrm{~A}$. Due to the switching action of power transistors, the output ripple of the power supply was significant. Since a transversing weld table was used, the weld torch could remain fixed.

Analysis of metal transfer was performed using highspeed photography (using NAC-16D type high-speed camera) with a xenon backlight. The arc image and arc light sensing signal waveform were recorded on one frame using synchronous imaging method.

The arc light sensor, with dimensions of $15 \mathrm{~mm}$ in diameter and $50 \mathrm{~mm}$ in length, was clamped on the welding torch (shown in Fig. 1). The light sensitive component is phototriode and the sensor worked well under any practical conditions with some protective design. In order to enlarge its dynamic range, a special control circuit was used. This circuit could adjust the sensitivity of phototriode according to the arc light intensity automatically.

For practical application, a PHILIPS single-chip microcomputer $80 \mathrm{C} 552$ (main frequency $16 \mathrm{MHz}$ ) was used in the sensing and control system. It received the arc light signal from the sensor and at the same time controlled the welding power source and wire feeder. It was also capable of sampling, processing data and judging droplet detachment, etc. Data could be transferred to a personal computer for further analysis. The welding parameters used as variables in the experiments were peak current, pulse frequency, shielding gas composition and contact-tube-to-work distance. Some of the experiments were performed on flat workpieces and

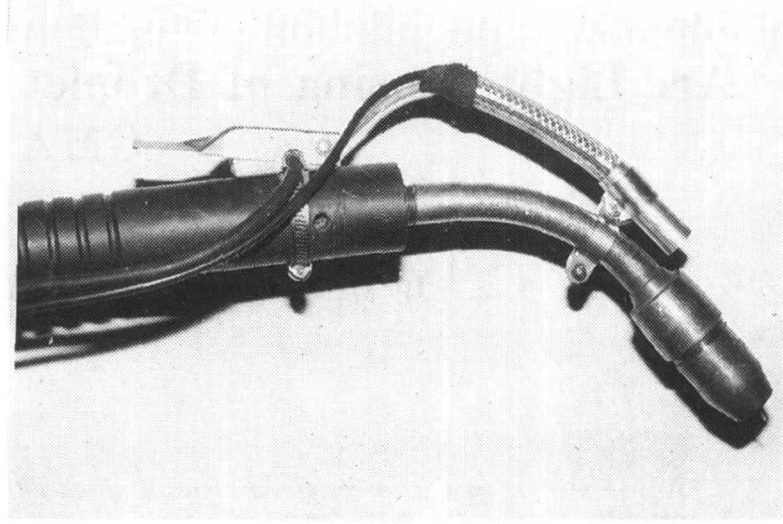

Fig. 1 The Photograph of arc light sensor clampled on a semiautomatic welding torch.

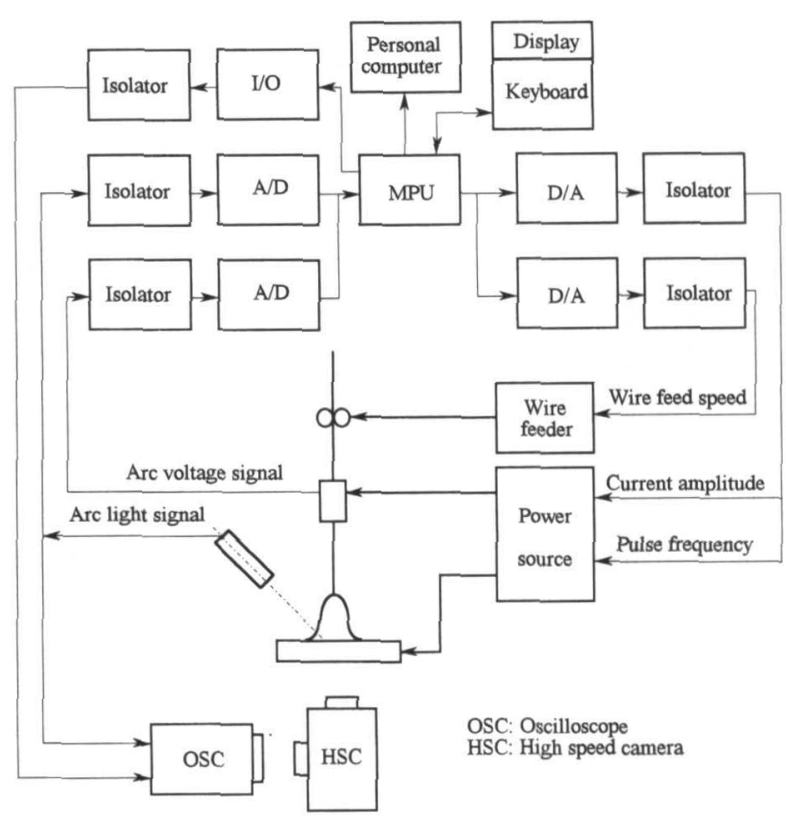

Fig. 2 The overall layout of the experimental equipment.

others were performed on specially shaped workpieces. All experiments were performed with automatic beadon-plate welding. Fig. 2 shows the overall layout of the experimental equipment. The purpose of the following experiments was to study the relationship between the arc light signal and the droplet detachment.

\section{Pulsed GMAW of Steel}

It is shown that the droplet detachment of spray transfer mode can be clearly indicated in arc light radiant flux signal in Fig. 3a, b with argon-rich shieding gases. The significant decrease in the arc light radiant flux signal corresponds to the droplet detachment. It has been proven indirectly in previous work ${ }^{27}$, and proven directly by high-speed photograph and synchronic signal 


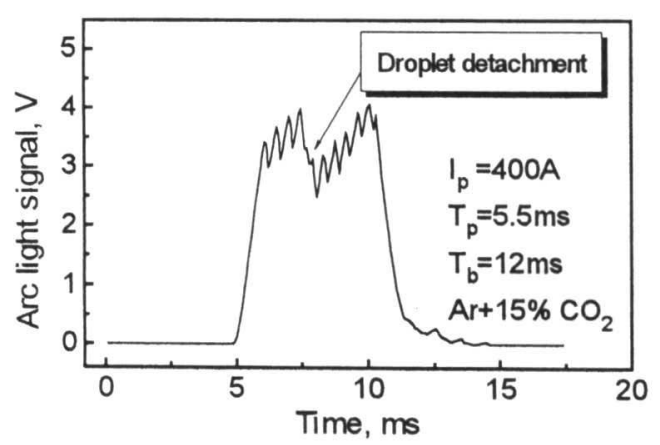

(a)

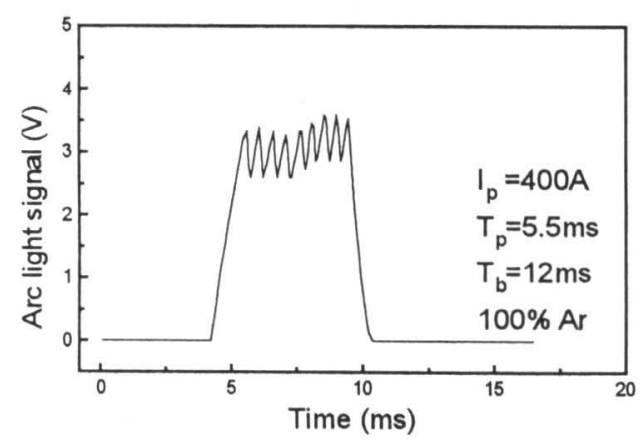

(c)

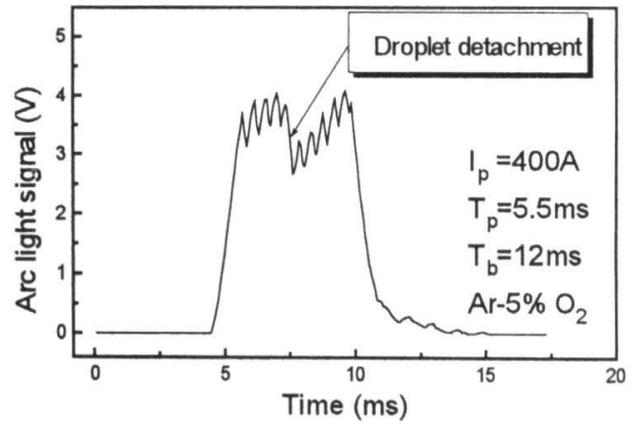

(b)

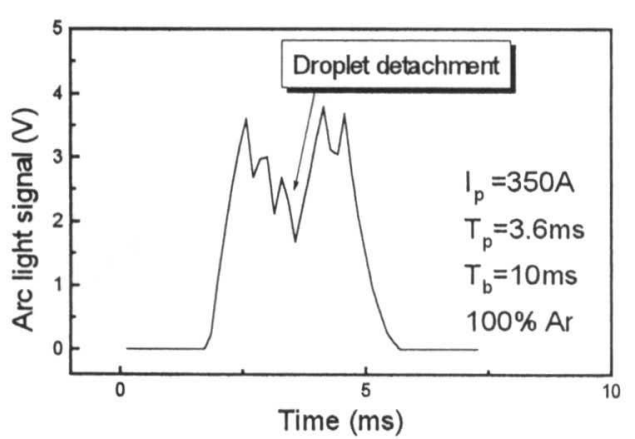

(d)

Fig. 3 Signals of arc light radiant flux in pulsed GMAW of steel and aluminum alloy.

$\begin{array}{ll}\text { (a) Steel, } \mathrm{Ar}-15 \% \mathrm{CO}_{2} & \text { (b) Steel, } \mathrm{Ar}-5 \% \mathrm{O}_{2}\end{array}$

$\begin{array}{ll}\text { (c) Steel, } \mathrm{Ar} & \text { (d) Aluminium, } \mathrm{Ar}\end{array}$

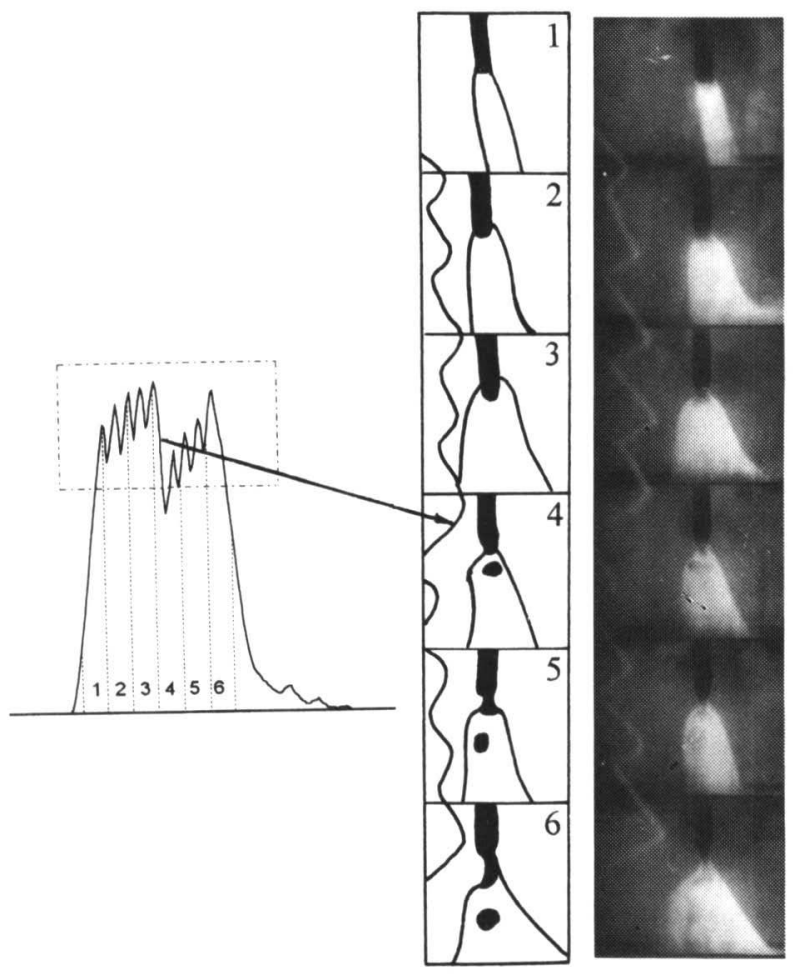

Fig. 4 The high-speed photograph of droplet transfer in pulsed GMAW of steel (1000 frames per second). $\mathrm{Ip}=400 \mathrm{~A}, \mathrm{Tp}=5.5 \mathrm{~ms}, \mathrm{~Tb}=12 \mathrm{~ms}, \mathrm{Ar}-15 \% \mathrm{CO}_{2}$ waveform (shown in Fig. 4) in this paper. In order to clearly show the variation in the arc light signal on the film, only part of the signal blocked with dot-dash line in Fig. 4 is taken. It can be seen that the decrease in arc light radiant flux signal strictly corresponds with the droplet detachment. The reliability of this phenomenon was proven by repeated experiments and the signal-tonoise ratio of the sensing method was high in spite of the large ripple on the output current of the welding power source.

However, arc light radiant flux signal cannot indicate droplet detachment in pulsed GMAW of steel shielded with pure argon (Fig. 3c). The reason for this phenomenon will be given in the discussion of this paper.

\section{Pulsed GMAW of Aluminum Alloy}

As shown in Fig. 3d, an obvious decrease in arc light radiant flux signal also occurs in pulsed GMAW of aluminum alloy. High-speed photography illustrates that the decrease in arc light signal strictly corresponds to droplet detachment as shown in Fig. 5. The sensing signal was proved to be reliable and of high signal-tonoise ratio through repeated experiments. 


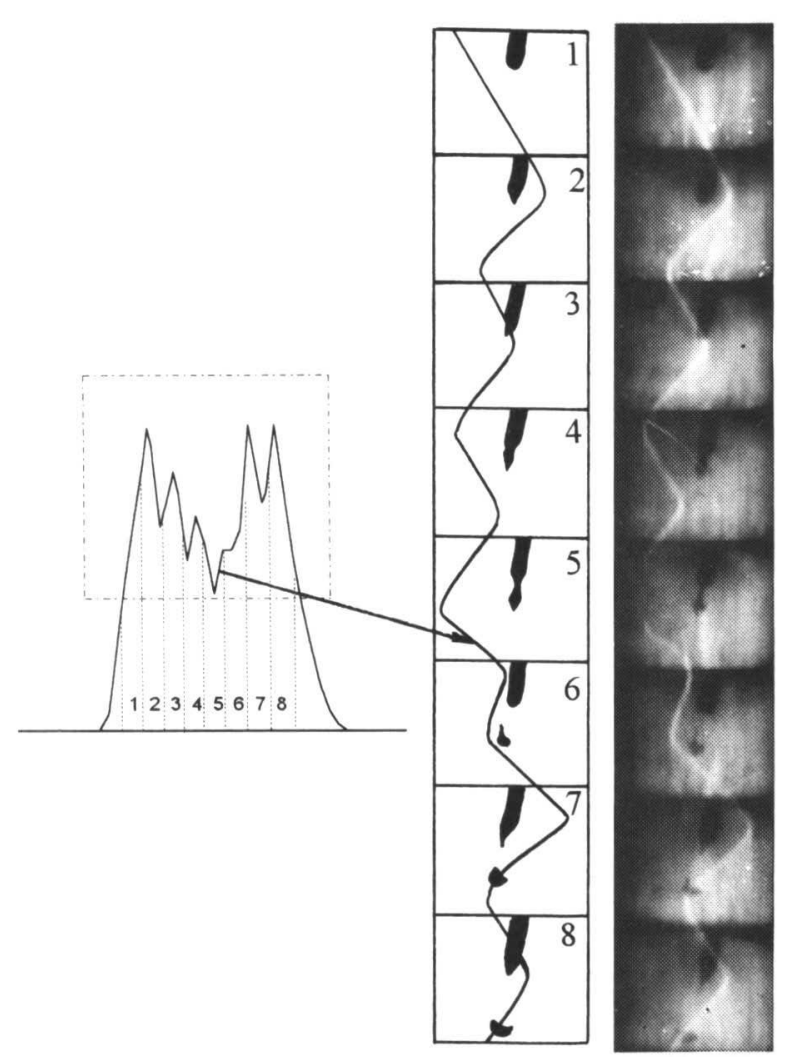

Fig. 5 The high-speed photograph of droplet transfer in pulsed GMAW of aluminum alloy (3000 frames per second).

$\mathrm{Ip}=350 \mathrm{~A}, \mathrm{Tp}=3.5 \mathrm{~ms}, \mathrm{~Tb}=10 \mathrm{~ms}, 100 \% \mathrm{Ar}$

3. Close-loop control of droplet transfer in pulsed GMAW of steel

On the basis of the relationship between variation of arc light radiant flux signal and droplet detachment, a close-loop control system for the droplet transfer process in steel welding was developed. The pulse peak current amplitude was set to 400 A. As shown in Fig. 6, during peak current time, as soon as the decrease in arc light exceeds the threshold selected through experimentation, a control signal is sent to the welding power source and the welding current immediately changes to background current. Neither streaming due to surplus pulse energy nor globular transfer due to lack of pulse energy occurs. With a control program developed by ourselves with MCS-51 language, the whole judgment time (including time of sampling, calculating to detect droplet detachment and sending the control signal if droplet detachment occurs) is less than 190 ns. Thus, the feedback loop freguency of this control exceeds, 5, 000 times per second and this high frequency can guarantee the accurate control of droplet transfer. In the pulse peak current time, the average value of arc light signal

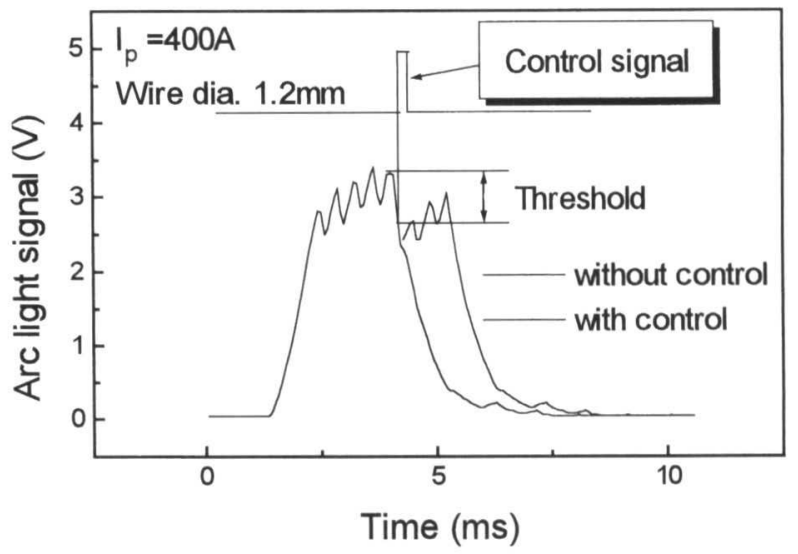

Fig. 6 Schematic of droplet detaching judgment in pulsed GMAW of steel.

was calculated. This value has a reliable linear relation with arc length. Therefore, arc length can be calculated from this value. A PID feedback mechanism is used in arc length control during background current time, the calculating time of which is less than $2.4 \mathrm{~ms}$. Background current amplitude is fixed to $50 \mathrm{~A}$. The background current time is calculated with PID calculation and adjusted to maintain the constant arc length. After setting peak current, wire feed speed and arc voltage, the pulse peak current time and background current time will be automatically adjusted by control system to maintain OPOD transfer mode and constant arc length. The reliability of the control process was improved by using relative threshold (15 percentage of the average value of arc light radiant flux signal during peak current). Although the absolute arc light signal value changes correspondingly when arc length changes within the range of 3 through $12 \mathrm{~mm}$, the control system is capable of maintaining OPOD transfer mode reliably. Fig. 7 shows the close-loop control process of pulsed GMAW of steel. Based on a number of high-speed photographs of control experiments, the reliability of the system in detecting droplet detachment has been proved to be $96 \%$. Error mainly resulted from the large ripple of the welding power source output. Fig. 8 is the photograph of bead formation of steel pulsed GMAW under droplet transfer close-loop control.

There is an another kind of OPOD research with optical metal droplet detector ${ }^{28}$, in which the relation between current waveform and metal droplet transfer is investigated in detail. In this system, $\mathrm{He}^{-\mathrm{Ne}}$ laser, optical lens and filters, and photo-transistor are used and high reliability is achieved. However, compared with the arc light sensor discussed above, this system is 


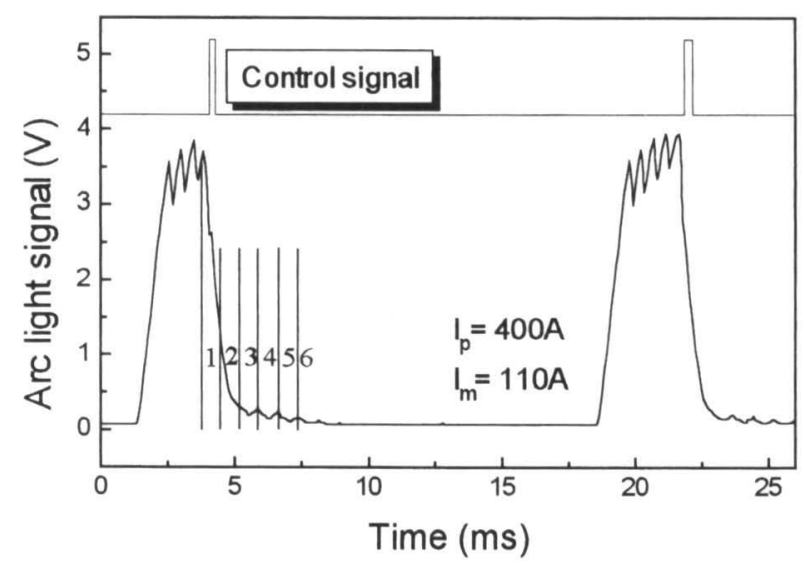
1
2
3
4
5
6

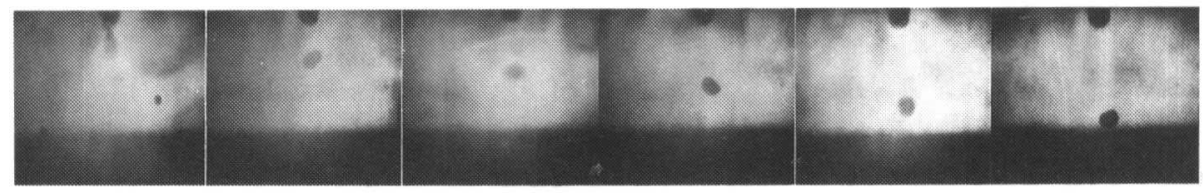

Fig. 7 The high-speed photograph of droplet transfer with OPOD control in pulsed GMAW of steel.

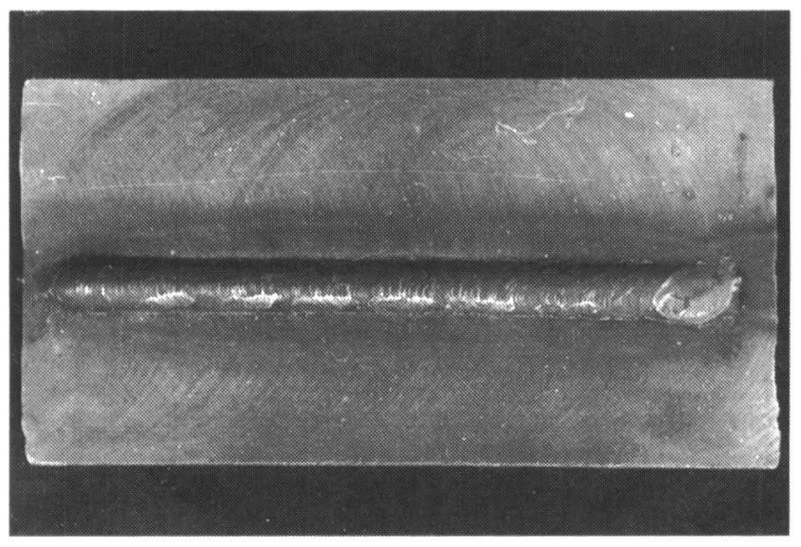

Fig. 8 The photograph of weld bead on front side with OPOD control in pulsed GMAW of steel.

relatively complicated and is not suitable for low cost automatic welding processes.

\section{Analysis of the Arc Light Signal}

\section{1) The physical essence of arc light radiation}

In GMAW with high welding current (more than $100 \mathrm{~A}$ ), the arc plasma is in local thermodynamic equilibrium (LTE) condition ${ }^{29,30)}$. In this case, the Kirchhoff rule can be used to calculate the spectrum intensity $B_{V}$ of the arc plasma ${ }^{31-33)}$.

$$
B_{\nu}=\frac{2 \cdot h \cdot \nu^{3}}{c^{2} \cdot e^{\frac{h \cdot \nu}{k \cdot T_{e}}-1}}
$$

where $B_{v}$ is the radiosity of unit stereo angle and unit frequency interval, $\mathrm{C}$ is light velocity, Te is electron temperature, $\mathrm{v}$ is frequency and $\mathrm{k}$ is boltzman constant. It is now assumed that arc light radiance is isotropic, then the radiosity $U_{v}$ can be represented by:

$$
\nu=\frac{4 \pi}{c} B_{\nu}
$$

The sensitive spectrum range of the sensor used in this work is narrow. The peak sensitive wave length is 820 $\mathrm{nm}$. In this case, hv/ $\mathrm{kt} \ll 1$, the condition of RaylleighJeans approximation is fulfilled, Equation (2) is approximately equal to :

$$
\nu=8 \pi \frac{\nu^{2}}{c^{3}} k T_{e}
$$

Under atmospheric pressure and with high current, the electron temperature is approximately equal to arc temperature ${ }^{31)}$. It is now assumed that heat losses are all due to conduction ${ }^{31)}$, then Elenbass-Heller rule ${ }^{32)}$ is fulfilled :

$$
\sigma E^{2}+\frac{1}{r} d\left(\frac{r \lambda d T}{d r}\right) / d r=0
$$

where $\mathrm{E}$ is the voltage gradient of $\operatorname{arc}, \mathrm{r}$ is radius, $\lambda$ is thermal conductivity and $\sigma$ is electric conductivity. As shown in Fig. 9, we can assume arc plasma luminary as a column, $R_{L}$ in radius and $L$ in length. With derivation in the Appendix A the mathematical model of arc radi- 
ant energy can be represented by :

$$
\begin{aligned}
U= & 8 \pi k \frac{\nu^{2}}{c^{3}}\left\{I E L\left[\left(\frac{1}{4}-\frac{\ln R_{L}}{2}\right) R_{L}^{2}+\left(\frac{\ln r_{a}}{2}-\frac{3}{8}\right) r_{a}^{2}\right]\right. \\
& \left.+\pi C_{2} L R_{L}^{2}+\pi C_{3} L r_{a}^{2}\right\}+C
\end{aligned}
$$

where $r_{a}$ is the radius of electric conducting area, $C, C_{2}$ and $\mathrm{C}_{3}$ are constants. Equation (5) shows that the direct influencing factors of arc radiation include welding current I, voltage gradient of arc $\mathrm{E}$, arc length $\mathrm{L}$ and the radius of plasma luminary $R_{L}$.

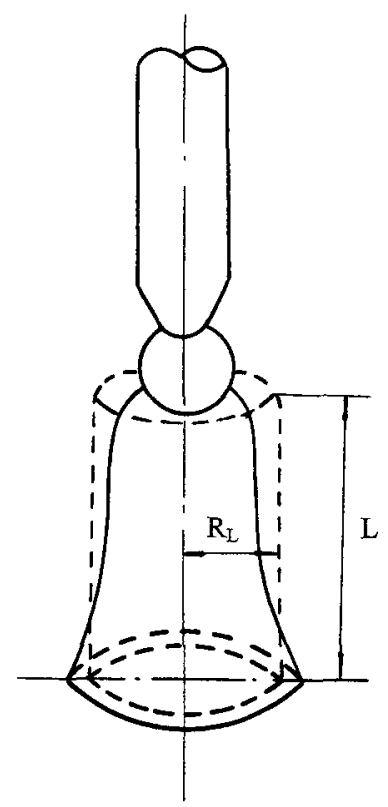

Fig. 9 The sketch of the arc plasma luminary.
2) The relationship between arc light radiant signal and arc plasma luminary geometry dimension (arc length $L$, radius $R_{\mathrm{L}}$ )

Equation (5) shows that both welding regime and arc plasma luminary geometric dimensions influence the arc light radiation. However, under spray transfer mode, no obvious variation occurs in welding current and voltage signal. It can be deduced that the decrease in arc light radiant flux signal which indicates droplet transfer results from the geometric dimension variation due to the droplet detachment. Next two groups of experiments were designed to demonstrate this deduction.

\section{a) The effect of variation in arc length $(L)$}

Specially shaped workpieces were used in this group of experiments, as shown in Fig. 10. The shielding gas was pure argon. Welding current range was 230 through $260 \mathrm{~A}$. Constant current output characteristic of the welding power supply was used to keep the current constant when arc length changed. The travel speed of the transversing table was set as high as possible $(60$ $\mathrm{cm} / \mathrm{min}$ ) to eliminate the arc self adjustment. The arc light signals were regressed to an expression correlating with the arc length and current:

$$
\Phi=\mathrm{P}_{1} \cdot \mathrm{I} \cdot \mathrm{L}+\mathrm{P}_{2} \cdot \mathrm{L}+\mathrm{P}_{3}
$$

where $\Phi$ was arc light radiant flux signal and $\mathrm{P}_{1}, \mathrm{P}_{2}, \mathrm{P}_{3}$ were constants. For current in $\mathrm{A}$, arc length in $\mathrm{mm}$, arc light signal in $\mathrm{V}$, the coefficients were $\mathrm{P}_{1}=0.002875$, $\mathrm{P}_{2}=-0.428$ and $\mathrm{P}_{3}=0.576$. The maximum relative deviation was $8 \%$. The experiments were performed under streaming transfer mode with stable arc profile. If the radius of plasma luminary is defined as a constant, the mathematical model represented by equation (5)
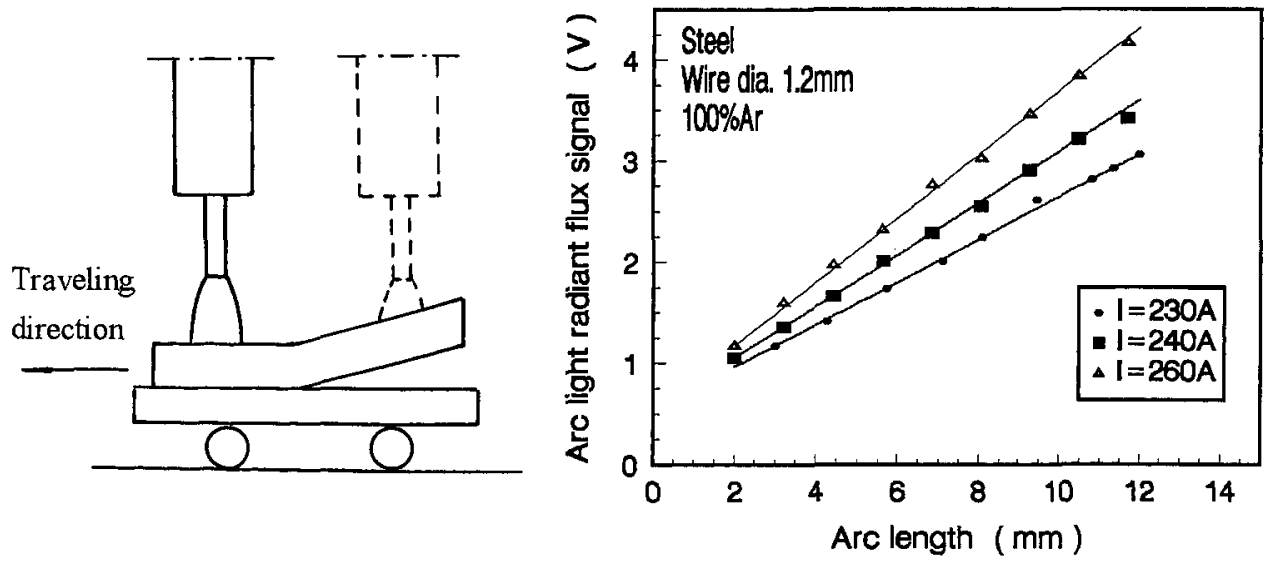

Fig. 10 Schematic of experiment with slope-shaped workpiece (a) and the relationship between the arc light radiant flux signal and the arc length with different welding currents (b). 
could be converted into the same pattern as equation (6). T.A. Siewert drew the same conclusion using statistics from a large amount of experimental results ${ }^{23}$. Fig. 11 shows relative variation of arc voltage and arc light signal versus arc length variation in experiments with slope-shaped workpieces. Because the absolute values of arc light and arc voltage signal are different, relative value of each signal are used to compare the sensitivity between them. The relative variation value of arc light signal is calculated through dividing instantaneous arc light signal value with the average value of arc light signal, so does arc voltage signal. It is obvious that arc light signal is more sensitive to arc length variation than arc voltage signal. The experiment results disscussed above also holds true for pulsed GMAW process of steel and aluminum alloy.

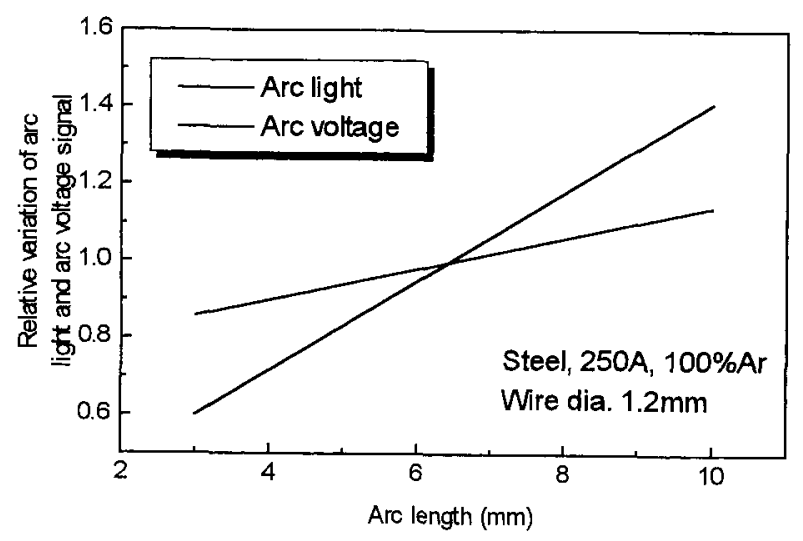

Fig. 11 The relative variation between arc voltage and arc light radiant flux signal versus arc length.
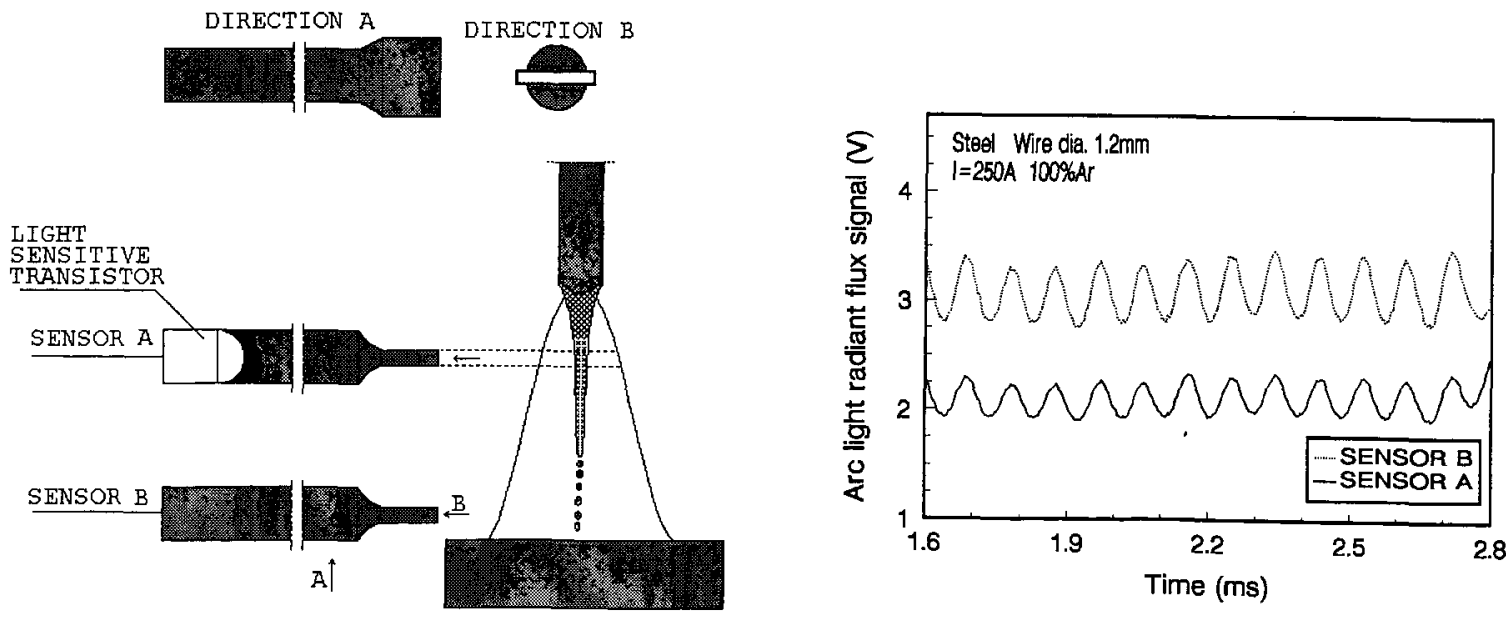

Fig. 12 The influence of arc plasma luminary radius on arc light radiant flux signal. 
This phenomenon shows there is a close relationship between shielding gas and characteristic arc light signal. Shielding gases influence the gradient of arc potential of arc column and change the behavior of arc and droplet transfer, resulting in the change of arc light radiant signal.

When $\mathrm{CO}_{2}$ content below $5 \%$ in agron-rich shielding gas $\left(\mathrm{Ar}-\mathrm{CO}_{2}\right)$, the characteristic variation of droplet detachment in arc light radiant flux signal is not obvious. This variation becomes obvious only when the $\mathrm{CO}_{2}$ content in shielding gas is higher. In steel welding arc with low $\mathrm{CO}_{2}$ content, arc roots can climb up from the lower surface of droplet to the electrode tip above the neck before droplet detachment. According to the principle of minimum voltage, the new arc current channels after arc roots climb should consume less energy than that of the original one, that is, the following expression (derivation is in Appendix B) should be fulfilled :

$$
\frac{I \cdot \rho}{\pi r_{n}^{2}}>E
$$

Where $r_{n}$ is the radius of the neck, $\rho$ is the specific resistance of molten metal, $\mathrm{E}$ is the arc potential gradient of arc column. The specific resistance of molten iron is high $(110 \mu \Omega \cdot \mathrm{cm}, 1070 \mathrm{~K})^{34}$. When pure argon shielding gas is used, E is relatively lower. Therefore, according to expression (7), the arc root can jump to the upper part of the neck easily and stay there for a relatively long time before droplet datachment. The neck becomes the main metal vapor source gradually. The reacting forces of vaporization press the neck to be a long liquid column till it breaks ${ }^{31}$. During this process, the droplet is enveloped by the arc column. For this reason, the arc length and metal vapor density do not change obviously due to droplet detachment and no characteristic arc light signal will occur.

When argon-rich shielding gases are used, $\mathrm{E}$ is relatively higher, then the expression (7) is difficult to be fulfilled. The arc roots are forced to constrict under the lower surface of the droplet, which becomes the main metal vapor emitting source. The arc roots jump to the upper part of the neck only when neck becomes very thin (radius $r_{n}$ is very small) and stay there only for a short time before droplet datachment. Because of the thermal inertia, the wire tip can not produce as much metal vapor as the previous metal vapor source at the lower part of the droplet immediately. Therefore, the metal vapor density will decrease after droplet detachment. The higher the $\mathrm{CO}_{2}$ or $\mathrm{O}_{2}$ content in shielding gas, the shorter the time the arc roots stay at the upper part of the neck before droplet detachment, and thus, the greater the variation of metal vapor density appears, the greater the characteristic arc light signal will be. When density of $\mathrm{CO}_{2}$ or $\mathrm{O}_{2}$ in shielding gas reaches certain value (i.e., $\mathrm{CO}_{2}$ content is $35 \%$ ), the change of the density of metal vapor caused by droplet detachment reaches its maximum, so the value of characteristic signal do not increase any longer.

In aluminum welding with pulsed or steady current, expression (7) is always difficult to be fulfilled due to the low specific resistance of aluminum alloy $(10.9 \mu \Omega \cdot \mathrm{cm}$, $923 \mathrm{~K})^{34}$. Arc roots cannot climb from the lower part of droplet to wire tip. Therefore, only the remarkable are length variation caused by droplet detachment results in an obvious change in arc light radiant flux signal. This sensing method is suitable both for pulsed and steady current GMAW of aluminum alloy.

\section{Conclusion}

1. The corresponding relationship between arc light radiant flux signal and droplet transfer in pulsed GMAW of steel and aluminum alloy was revealed.

2. A novel practical arc light sensing system was developed. The system can detect the droplet detachment reliably in steel pulsed GMAW with argon-rich shielding and aluminum alloy GMAW with steady or pulsed current.

3. A colse-loop droplet transfer control system with arc light sensing was developed for pulsed GMAW of steel. The welding process with this control system is stable, quiet, spatter free and good weld formation is acquired.

4. A mathematical model of the arc light radiation was set up. With the help of this model, the mechanism of variation of the arc light radiant flux singnal caused by droplet detachment can be better understood.

5. The influence of different shielding gases on the formation of the characteristic signal was discussed.

\section{References}

1) J.F. Santos: Metal Transfer in Consumable Electrode Arc Welding-Time for a Reassessment, IIW Doc. No. 212-78091, pp. 1-11.

2) S. Liu, T.A. Siewert, H. Lan: Metal Transfer Mode in Gas Metal Arc Welding, Proc. of the 2nd International Conf. on Trends in Welding Res., Gatlinburg, Tennessee, USA, May 14-18, 1989, pp. 475-479.

3) R. Lahnsteiner: Advanced Synergic Inverter Power-source 
and Wirefeed System for GMA-Welding with Integrated Quality Control System, Proc, International Conf. on Advanced Techniques and Low Cost Automation, Beijing, China, September 5-6, 1994, pp. 204-213.

4) S. Ueguri, K. Hara, H. Komura : Study of Metal Transfer in Pulsed GMA Welding, Weld. J., Vol. 64 (1985), No. 8, pp. $242 \mathrm{~s}-250 \mathrm{~s}$.

5) J.F.Collard: Adaptive Pulsed GMAW Control: The Digipulse System, Weld. J., Vol. 69 (1988), No. 11, pp. 35-38.

6) H. Matsui, H. Suzuki : The Effects of Current Wave Shape and Electrode Wire Contents on Metal Transfer in High Speed Pulsed MAG Welding, IIW Doc., No. 212-752-90, pp. 104-116.

7) J.Ma, R.L. Apps: New MIG Process Results from Metal Transfer Mode Control, Welding \& Metal Fabrication, Vol. 51 (1983), No. 4, pp. 168-175.

8) J.C. Dutra: Computerized Procedure of Metallic Drop Transfer Analysis for the Determination of Pulsed Welding Variables, IIW Doc. No. X II-1171-90, pp. 234-244.

9) Y.-S. Kim, T.W. Eagar: Metal Transfer in Pulsed Current Gas Metal Arc Welding, Weld. J., Vol. 74 (1993), No. 7, pp279s-287s.

10) Q.L. Wang, L. Zhang: The Research of Synergic Pulsed Welding Power Supply, Joining and Cutting, 1990, No. 8, pp. 1-7.

11) S. Uegari, United States Patent, 4438317, 1984.

12) R.A. Willgoss: Mathematical Model Predicts Equilibrium, Welding \& Metal Fabrication, Vol.52 (1984), No.9, pp. 340 -351 .

13) J.A. Johnson, N.M. Carlson, H.B. Smartt, D.E. Clark : Process Control of GMAW: Sensing of Metal Transfer Mode, Weld. J., Vol. 72 (1991), No. 4, pp. $91 \mathrm{~s}-99 \mathrm{~s}$.

14) J.A. Johnson, N.M. Carlson, H.B. Smartt: Detection of Metal-transfer Mode in GMAW, Proc. 2nd International Conf. on Trends in Welding Res., Gatlinburg, Tennessee, USA, 14-18 May, 1989, pp. 377-381.

15) J.H. Chen, D. Fan, Z.Q. He, J. Ye, Y.C. Luo: A Study of the Welding Mechanism for Globular Metal Transfer from Covered Electrodes, Weld. J., Vol. 70 (1989), No. 4, pp. 145s$150 \mathrm{~s}$.

16) D.E.Clark, C.L. Buhrmaster, H.B. Smartt: Drop Transfer Mechanisms in GMAW, Proc. 2nd International Conf. on Trends in Welding Res., Gatlinburg, Tennessee, USA, 14-18 May, 1989, pp. 371-375.

17) Q.L. Wang: The Study on the Relation Between Arc Sound and Arc phenomena, Science Report of Harbin Institute of Techology, Vol. 78 (1981), No. 9, pp. 124-129.

18) R.B. Madigan, T.P.Quinn, T.A. Siewert, Sensing Droplet Detachment and Electrode Extension for Control of Gas Metal Arc Welding, Proc. 3rd International Conf. on Trends in Welding Res. Gatlinburg, Tennessee, USA, 1989, pp. 9991002 .

19) T. Araya, Y. Endo: Study on Pulse Current MIG Welding of Aluminum, Journal of the Japan Welding Society, Vol. 50 (1981), No. 2, pp. 75-81.

20) A. Gulsoz, D. Rehfeldt: Melting Behavior of Basic Electrodes in Direct and Alternating Current Welding, IIW Doc., No. 212-780-91.

21) L. Zhang: "Arc Light Sensing and Real-Time Control of Droplet Transfer in Pulsed MIG (MAG) Welding", Ph. D. dissertation, Harbin Institute of Technology, 1991.
22) G. Adam, T.A. Siewert : Sensing of GMAW Droplet Transfer Modes Using an ER100s-1 Electrode, Weld. J., Vol. 71 (1990), No. 3, pp. 103s-108s.

23) J.C. Needham, What Do You Mean By Voltage?, The Welding Institute Research Bulletin, Vol. 26 (1985), No.9, pp. 311-316.

24) P.R. Heald, R.B. Madigan, T.A. Siewert, S. Liu: Mapping the Droplet Transfer Modes for an ER100s-1 GMAW Electrode, Weld. J., Vol. 75 (1994), No. 2, pp. 38s-44s.

25) E.M. Trindade, C.J. Allum: Characteristics in Steady and Pulsed Current GMAW, Welding \& Metal Fabrication, Vol. 52 (1984), No. 8, pp. 264-272.

26) K. Ohshima, M. Abe, T. Kubota: Sampled-Data Control of Arc Length in Mig Pulsed Arc Welding, The Journal of Japanese Welding Institute, Vol. 51 (1982), No.8, pp. 82-89.

27) Q.L. Wang, L. Zhang: Arc light Sensing of Droplet Transfer in GMA Welding and the Real-time Control of One Pulse One Droplet, Proc. 40th Annual Conf. of the Welding Technology Institute of Australia, 29 June-3 July, 1992.

28) H. Maruo, Y. Hirata, Y. Noda : Effects of Welding Current Waveform on Metal Transfer and Bead Formation in Pulsed MIG Wedling-Study on Pulsed Arc Welding (Report 1), Trans. JWRI, Vol. 2 (1984), No. 1, pp. 11-18.

29) Y.L. Song: "Spectroscopic Study and its Application in Welding Arc Plasma", Ph. D. dissertation, Harbin Institute of 'Technology, China, 1991.

30) Y.L.Song, J.Y.Li: Thermo-equilibrium in Welding Arc Plasma, Transactions of China Welding Institution, Vol. 15 (1995), No. 2: pp. 138-145.

31) K. Ando: “Arc Physical Phenomena”, Mechanical Industry Press, BeiJing, China, 1985.

31) Z.Y. Guo: "Arc and Thermal Plasma", Science Press, BeiJing, China, 1986.

33) C.B. Derliesven: "Physics and Technology of gas Discharging”, Science press, BeiJing, China, 1980.

34) Z.F. Zhou : "Welding Metalurgy and Weldability of Metal", Mechancal Industry Press, BeiJing, China, 1980.

\section{Appendix}

A. According to the principle of Ohm with differential pattern:

$$
j_{r}=\sigma E
$$

where $j_{r}$ is current density, $\sigma$ is electric conductivity, $E$ is the voltage gradient of arc. Substitute $j_{r}$ in equation (4) in the paper we obtain:

$$
j_{r} E=-\frac{1}{r} d\left(\frac{r \lambda d T}{d r}\right) / d r
$$

It is now assumed that $\lambda$ is constant, integrate $T$ in equation (2a), we obtain:

$$
T=-\frac{I E r^{2}}{4 \pi R^{2} \lambda}+C_{1}
$$

where $c_{1}$ a constant. Substitute $T$ in equation (3) in the paper, we obtain :

$$
\nu=8 \pi k \frac{v^{2}}{c^{3}}\left(-\frac{I E r^{2}}{4 \pi R^{2} \lambda}+C_{1}\right)
$$


When $\mathrm{r}>\mathrm{ra}, \sigma=0$, equation (4) in the paper can be converted to:

$$
\lambda d T=-\frac{I E}{2 \pi \mathrm{r}} d r
$$

Integrate $\mathrm{T}$ in equation (5a), we obtain :

$$
T=-\frac{I E \ln r}{2 \pi \lambda}+C_{2}
$$

where $c_{2}$ is a constant. Substitute $T$ in equation (3) in the paper, we obtain:

$$
\nu=8 \pi k \frac{v^{2}}{c^{3}}\left(-\frac{I E r^{2}}{4 \pi R^{2} \lambda}+C_{2}\right)
$$

The radiant flux $\phi$ can be obtained by differentiating arc radiant energy with respect to time. The rule of the variation of arc radiant flux can be analyzed by analysis of radiant energy. It is now assumed that arc column is a optical lamina which does not absorb radiant energy. Integrate $\mathrm{U}_{\mathrm{v}}$ over volume, we obtain the radiant energy of the whole arc column, $R_{L}$ is defined as the radius of plasma luminary :

$$
\begin{aligned}
U= & \iiint U_{v} d \mathrm{v}=\int_{0}^{L} \iint U_{v} d S d l=L \iint U_{v} d S \\
= & L\left(\int_{0}^{r_{a}} 2 \pi r U_{v} d r+\int_{r_{a}}^{R_{L}} 2 \pi r U v d r\right) \\
= & 8 \pi k \frac{v^{2}}{c^{3}}\left\{I E L\left[\left(\frac{1}{4}-\frac{\ln R_{L}}{2}\right) R_{L}^{2}+\left(\frac{\ln r_{a}}{2}-\frac{3}{8}\right) r_{1}^{2}\right]\right. \\
& \left.+\pi C_{2} L R_{L}^{2}+\pi C_{3} L r_{1}^{2}\right\}
\end{aligned}
$$

where $U$ is the radiant energy of the whole arc column within unit frequency interval, $c_{3}$ is a constant. Considering other radiant sources, such as welding puddle, and energy loss to some extent, a constant $C$ should be added to the calculated result. Thus, $U$ can be represented as :

$$
\begin{aligned}
U= & 8 \pi k \frac{v^{2}}{c^{3}}\left\{\operatorname{IEL}\left[\left(\frac{1}{4}-\frac{\ln R_{L}}{2}\right) R_{L}^{2}+\left(\frac{\ln r_{a}}{2}-\frac{3}{8}\right) r_{a}^{2}\right]\right. \\
& \left.+\pi C_{2} L R_{L}^{2}+\pi C_{3} L r_{a}^{2}\right\}+C
\end{aligned}
$$

B. According to the principle of minimum voltage, when the arc roots climb to the electrode tip above the neck from the droplet bottom, it should be fulfilled that:

$$
\frac{U_{n}}{L_{n}}>E
$$

where $U_{n}$ is the potential cross the neck, $L_{n}$ is the length of neck, $E$ is the voltage gradient of the arc column. It is now assumed that the neck is a liquid metal column with length of $L . R_{n}$ is defined as the resistance of this liquid metal column, $\rho$ is the resistivity of molten iron. Then $\mathrm{U}_{\mathrm{n}}$ can be represented as :

$$
U_{n}=I \cdot R_{n}=\frac{I \cdot \rho \cdot L}{S}=\frac{I \cdot \rho \cdot L_{n}}{\pi r_{a}^{2}}
$$

Substitute $\mathrm{U}_{\mathrm{n}}$ in the equation (1b), we obtain :

$$
\frac{I \cdot \rho}{\pi r_{a}^{2}}>E
$$

